\title{
Evaluación Energetica y Propuesta de Mejoras Tecnologicas en un Secadero de Ladrillos
}

\author{
Energy Audit and Technological Improvements Proposed in a Brick Ceramic \\ Dryer
}

\author{
Milton Fabián Coba Salcedo, Lisandro Vargas Henríquez, Elvis Salcedo Valdez, Jahir Alfonso \\ Pinto Ariza \\ Programa Ingeniería Mecánica, Facultad de Ingeniería, Universidad del Atlántico, Barranquilla, Colombia. \\ miltoncoba@mail.uniatlantico.edu.co
}

\begin{abstract}
Resumen-Se analizó una situación de vital importancia para la industria Ladrillera barranquilla LTDA., ya que el país se encuentra en un proceso de cambio, debido a la globalización y el tratado de libre comercio, TLC, y haciendo uso de las líneas de investigación, planteadas por la facultad de Ingeniería de la Universidad del Atlántico; "Uso eficiente y racional de la energía", la cual aborda con rigor lo relacionado con el Uso Racional de Energía y Automatización de los Procesos Industriales.

Por lo anterior, se realiza el estudio, "Evaluación energética y mejoras tecnológicas, en el proceso de secado de la empresa ladrillera barranquilla LTDA.", con el fin de determinar y revisar puntos de consumo energéticos dentro del proceso de secado, debido a las perdidas productivas que se venían generando. De esta forma establecer estrategias que favorezcan la utilización adecuada de los recursos energéticos. Proponiendo cambios que puedan ser de gran ayuda para la empresa y que a mediano o largo plazo evidencien avances significativos en la disminución de costos conllevando a mejoras en la producción, consumo energético y la ampliación de perspectivas técnicoeconómico para la empresa.
\end{abstract}

Palabras clave - Uso eficiente de la energía, Ahorro en consumos energéticos, Diagnostico energético, Mejoras energéticas.

Abstract-This research project analyze a situation of vital importance to the making brick industry in Barranquilla since Colombia is in a changing process due to globalization and freetrade agreement (FTA), and using the research lines suggested by the Faculty of Mechanical Engineering of Atlántico University; "Efficient and rational use of energy" which deals with everything is related to the rational use of energy and the automation of industrial processes.

Therefore, this project "Energy evaluation and technological improvements in the drying process of the making-brick company Barranquilla LTDA" is conducted to determine and check how the power consumption works in the drying process since losses in the production were observed for a while. In this way, this paper develops strategies in order to benefit the appropriate use of energy resources. Helpful changes are proposed as they may be favorable for the company in a medium or long term show. These changes will show a meaningful progress in cost reduction which will entail to improvements in production, energy evaluation and the expansion of technical and economic perspectives.

Key Word - Ceramic Bricks, Audit Energy, Kiln Ceramic, Technological Proposal.

\section{INTRODUCCIÓN}

Aunque que en Colombia existen reservas energéticas muy amplias, es necesario concientizar a las empresas nacionales sobre el uso racional de la energía y las posibles consecuencias económicas que esto acarrea, para beneficio de ellas. La ejecución de un sistema de gestión energética es una herramienta de vital importancia en el manejo de este tema, y brinda una visión amplia sobre las potenciales medidas de ahorro que se pueden tomar en la empresa.

Para toda empresa productora es trascendental mantener un equilibrio entre producción y consumo energético, sin embargo esta tarea es ardua y trae consigo un estricto monitoreo de estas variables para visualizar el comportamiento de la empresa, cuantificar las pérdidas energéticas y aplicar correctivos si es necesario [1]. Cuando se cuentan con herramientas que suministran parámetros de control es más fácil desarrollar tácticas de ahorro que produzcan un impacto económico substancial para la rentabilidad del negocio.

Cualquier proceso productivo se encuentran ligado a los consumos energéticos, ya sean eléctricos, a gas natural, u otros como combustibles fósiles como el carbón mineral, que son imperativos y no se pueden eliminar, lo único que se puede hacer es disminuirlos hasta lograr una "armonía" entre estas variables, "producción/consumo".

Los procesos productivos que más generan pérdidas son aquellos que involucran generación de calor, debido a la inestabilidad en las variables que estos manejan: presión y temperatura. La variación inesperada de estas variables 
acarrea un flujo de calor indeseado que se traduce en pérdidas energéticas que afectan el buen funcionamiento de los equipos involucrados en el proceso productivo y en consecuencia disminuyen la eficiencia global de la empresa.

El actual cambio propuesto en el modelo socio-económico ha determinado la clara necesidad de lograr una mayor competitividad y productividad, con el fin de ocupar un lugar atractivo en el mercado y pretender ser líderes en el ámbito nacional como internacional. De tal manera, una estrategia útil es la búsqueda de ahorro sustancial es el consumo de energía [2].

La mayoría de ladrilleras, son industrias que carecen hasta el momento de tecnología moderna para los procesos de producción, que tienden a incurrir en costos innecesarios, lo cual los sitúa en gran desventaja con otras industrias que han dado grandes avances en sus procesos de modernización permitiéndoles una alta eficiencia energética y un bajo impacto sobre el medio ambiente [3].

En este estudio se han evaluado las pérdidas energéticas en el proceso de Secado de la Empresa Ladrillera Barranquilla LTDA, el objetivo planteado es la realización de la evaluación energética de este proceso, debido a las grandes pérdidas de material final que se generan en la empresa, y debido a que el proceso de secado es un proceso critico dentro de la producción de ladrillos, es vital intervenir en este, para tener claro que está sucediendo y como mejorarlo [4].

Para esto se tomara información durante tres meses, como lo son gastos energéticos, producción, perdidas, y otros. Dando como resultado la identificando de los principales consumos y permitiendo entonces platear medidas de ahorro a corto, mediano y largo plazo, así como los costos que estas pérdidas representen, estableciendo estrategias que favorezcan la utilización adecuada de la energía [5].

\section{METODOLOGIA}

La metodología seguida en este estudio comprende los siguientes pasos.

A. Recopilación de Información Preliminar:

Se han estudiado las Normas y regulaciones energéticas específicas para la industria del ladrillo [6]. Se han recopilado información sobre las características de operación de la ladrillera. Las especificaciones técnicas de los sistemas de energía, para el proceso de secado. La ficha técnica de procedimientos de operación y mantenimiento de sistemas de energía, equipo e instalaciones, para el proceso de secado.

B. Reconocimiento de la Ladrillera:

Observación directa, conocimiento de la operación y el funcionamiento, enfocado a identificar los centros de potencial ahorro de energía u mejoras en el proceso de secado.

C. Revisión de Documentación:

Reconocimiento de planos arquitectónicos y eléctricos disponibles.

Procedimientos de operación y mantenimiento, bitácoras, facturas de consumos de energía con tres meses de anterioridad, debido a la poca información y control que maneja la empresa en sus procesos [7].

D. Recopilación de Información Complementaria: Identificación de fuentes potenciales de consumo de energía dentro del proceso de secado de la Ladrillera Barranquilla Ltda.

\section{E. Mediciones en la Empresa:}

Medir y determinar los consumos de las energías que intervienen en el proceso de secado. Realizar encuesta de conocimientos acerca de la utilización adecuada de energía. Realizar mediciones a los equipos que sea necesarios para validar o materializar los parámetros de operación.

\section{F. Interpretación de la Información:}

Calcular la cantidad de energía requerida para la producción de una unidad de ladrillo. Análisis comparativo de puntos de energía y costos de consumo. Realizar cálculo de costos, ahorró de energía y retornos. Realizar informe final de los resultados encontrados [8].

\section{G. Propuestas y Recomendaciones:}

Descripción de los posibles ahorros con su impacto energético, analizando costos, beneficios y retornos. Elaboración de conclusiones y recomendaciones [9].

\section{DESCRIPCION DEL PROCESO DE SECADO}

El proceso de fabricación de un producto con base en arcilla como los ladrillos o tejas, está formado por tres grupos de operaciones. Primero, la preparación de materias primas y productos intermedios (donde ocupan un lugar destacado tanto las arcillas, como las fritas, esmaltes y colorantes). Segundo, la obtención del producto acabado, listo para ser utilizado en el sector de la construcción. Y, en tercer lugar, la distribución, es decir, la colocación del producto acabado en manos del consumidor final.

La materia prima principal del proceso de fabricación de ladrillos como se ha mencionado es la arcilla. Existe una gran variedad de arcillas utilizadas en la fabricación de cerámica, las diferencias se reflejan en su composición química que afecta directamente en las propiedades físico-químicas de los productos obtenidos y en las emisiones residuales, generadas durante todo el proceso. También se utilizan en mucha menor proporción, otras sustancias tales como: cuarzo, arena, feldespato, granito, etc.

Entre las características más importantes de este sector industrial se pueden citar:

v Gran disparidad de tamaños y tecnificación de las instalaciones productivas.

Fabricación de una gran variedad de productos.

v Dispersión Geográfica de los centros de producción (ladrillos y tejas).

Concentración de los centros de producción en determinadas zonas (pavimentos revestimientos cerámicos).

Este estudio se enfoca en el proceso de secado de ladrillos, Figura 1. Teniendo en cuenta que el secado se da por dos vías, 
la natural que es dejar secar el producto en espacios abiertos por medio del aire circundante y el secado de manera artificial el cual se realiza en esta empresa por medio de dos secaderos uno grande y otro pequeño.

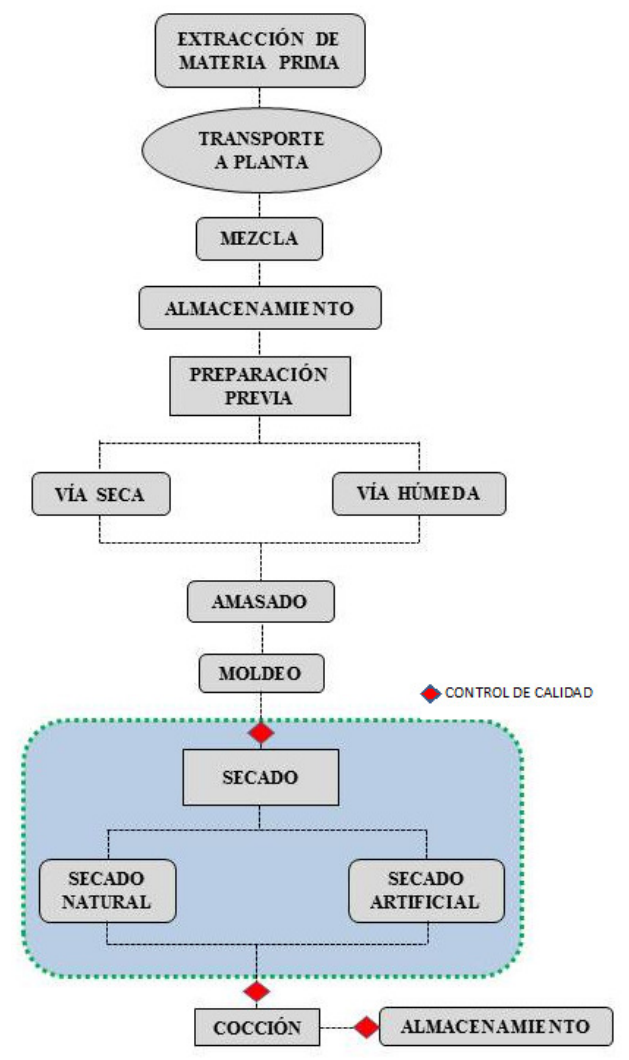

Figura 1. Esquema de procesos industria en la fabricación de ladrillos.

El secado es una de las fases más delicadas y transcendentes del proceso de fabricación de ladrillos, debido a que en buena parte es el responsable del producto que saldrá de los hornos. Un secadero con problemas se puede convertir en un cuello de botella en el que se estrangula toda la producción y rentabilidad de una instalación.

El secado, por otra parte, es una operación muy compleja en la que convergen múltiples factores: naturaleza de la arcilla, grado de preparación y homogeneización, tensiones que han tenido lugar durante el moldeo, diseño y formato de la pieza, uniformidad o des-uniformidad en el secado, etc.

Con la optimización del proceso de secado lo que se pretende es lograr el secado de las piezas con el mínimo consumo térmico y eléctrico y sin que se produzcan defectos.

El proceso de secado como se ha comentado se realiza de dos formas en esta empresa, una la natural en donde los trabajadores llevan el material hasta los secaderos naturales que están distribuidos en tambos, la duración del material en este proceso varia según el clima, ya que si hacen días calurosos permanecerán aquí entre dos y tres días, pero si los días son lluviosos pueden durar entre cinco y ocho días para continuar con el proceso. En el caso de una elevada producción, el material es trasladado a secaderos artificiales. Estos son alimentadas con una cámara de combustión donde se quema carbón, a su vez tiene unos ventiladores, que tiene la función de extraer el calor hasta los secaderos, dentro de estos hay recirculadores que distribuye el calor por todo el secadero y así secar de manera homogénea todo el material.

En la empresa Ladrillera Barranquilla el tipo de secadero instalada es un secadero tipo túnel, de estos hay dos un pequeño y uno grande. En estos se logra mejor rendimiento térmico que por ejemplo en secaderos de cámaras, requiriéndose menor mano de obra, pero el coste de inversión es más elevado.

En general, en estos secaderos las piezas se cargan sobre carretillas las cuales circulan por unas vías dispuestas a lo largo del túnel de secado. Para el sistema de recirculación de aire en el interior del secadero se utilizan recirculadores llamados ventiladores auto-viajantes de gran aspa. Estos recirculadores son ventiladores de tiro axial que viajas por una vía que se sitúa como pared central de las carretillas, Figura 2.

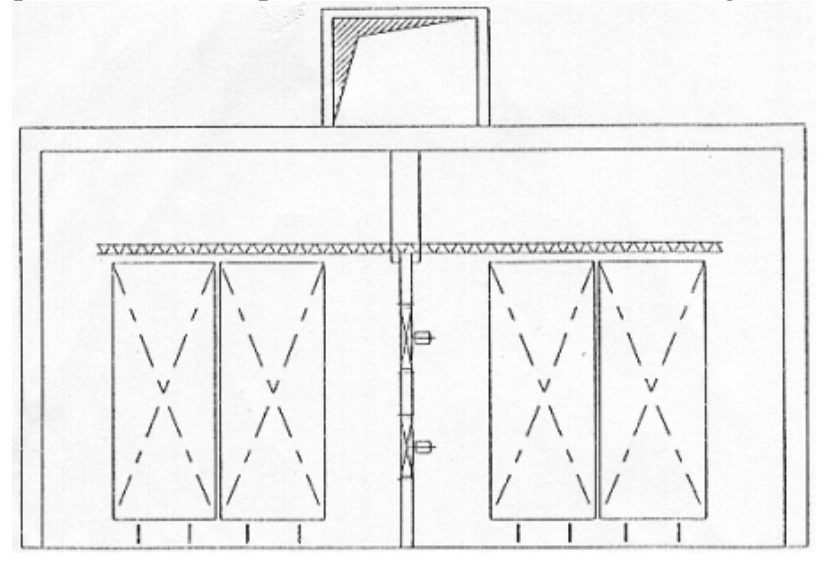

Figura 2. Esquema del proceso de secado en estudio.

\section{EVALUACIÓN ENERGETICA}

La primera impresión que observa al visitar la empresa Ladrillera Barranquilla, es de grandes cantidades de material de desperdicio, ya que entrono al $15 \%$ del material que sale de los hornos, es material quebrado o roto, cuando ese porcentaje debería estar por debajo del 5\%, Figura 3-4.

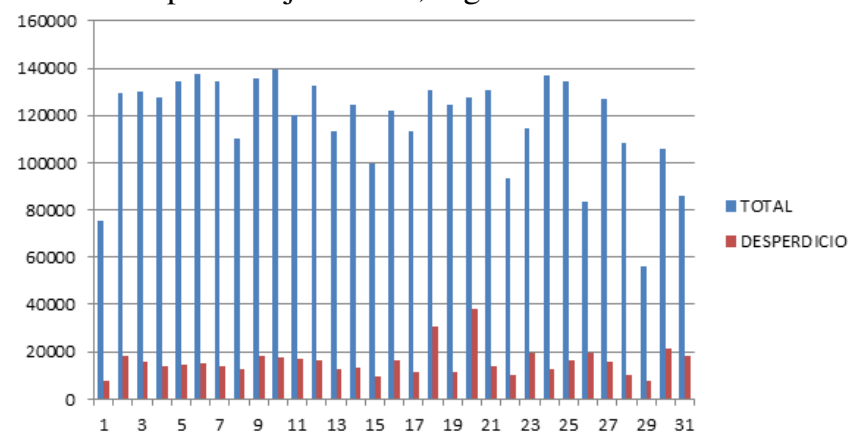

Figura 3. Cantidad de desperdicio vs producido mes de Mayo 2012. 


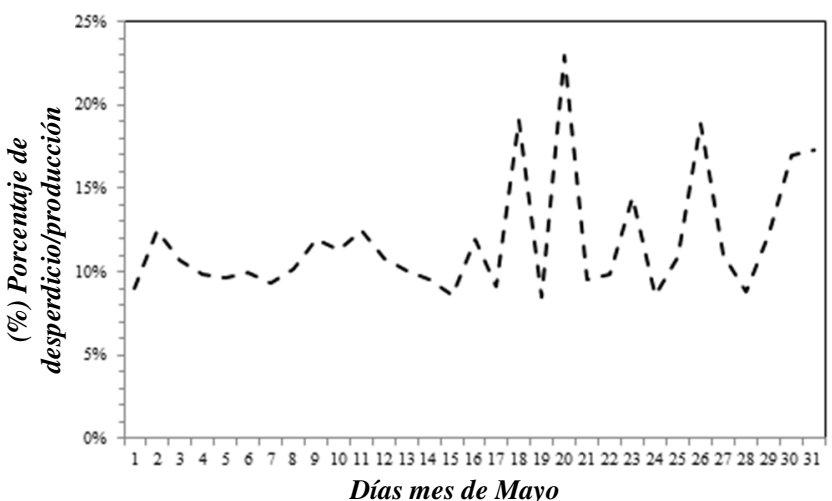

Figura 4. Porcentaje de desperdicio/producción mes de Mayo 2012. Como se comento anteriormente el proceso de cocción está determinada por la humedad a la que entra el material al horno, por eso el secado es una etapa primordial en la fabricación de ladrillo, ya que de este dependerá la calidad del material que saldrá de los hornos.

Para tener total control del proceso de secado durante el tiempo de estudio se tomaron medidas de $(\%)$ de desperdicio, producción, consumos energéticos (eléctricos, combustible, mano de obra, mantenimiento, etc...), humedades residuales.

Teniendo en cuenta que el secado se realiza de dos formas la artificial y la natural, es necesario saber qué cantidad de este material que llega al horno se da por medio del secado artificial.

A partir de los datos recopilados se observa que la cantidad de material que ingresa a los hornos procedente de los secaderos artificiales es aproximadamente el 53\% de la demanda del horno, lo cual indica que solamente se esta controlando ese porcentaje de material que entre a los hornos diariamente, Figura 5.

Cabe anotar que para realizar el estudio comparativo en las gráficas se tomó como referencia el mismo tipo de bloque (No. 4), debido a que este es el de mayor demanda y volumen de producción, y referente de la empresa [10].

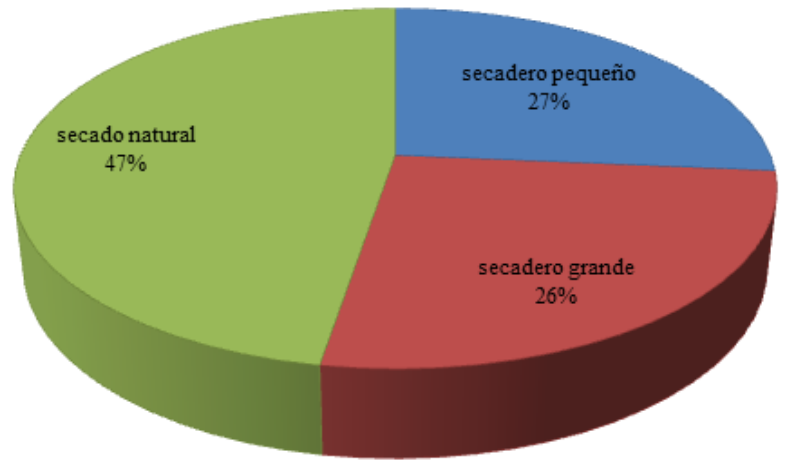

Figura 5. Secado artificial vs secado natural.

\section{A. Diagrama de Consumos Energéticos y Producción Equivalente}

Como herramientas para facilitar y realizar la evaluación energética de manera adecuada, es necesario tener un diagrama de bloque el cual muestra las energías que intervienen en el proceso, y el producto que se obtiene del proceso, Figura 6.

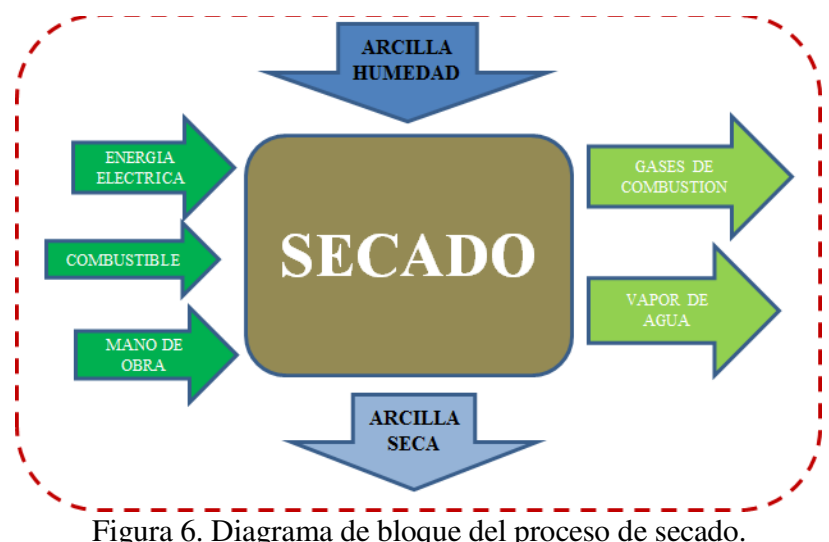

Figura 6. Diagrama de bloque del proceso de secado.

Además es importante definir un parámetro de producción que sea comparativo con todos los productos que se fabrican para poder evaluar por igual, es decir, tener una medida de producción equivalente, esto es muy importante debido a que se maneja diferentes tipos de producto y para su evaluación se debe tener en una unidad igual a todos, en este estudio se trabajara con kilogramos producido usando los informes diarios tomados en la planta luego multiplicarlo por su peso y trabajar con la referencia número 4 cuando se trate de unidades. A continuación se muestra en la Tabla 1, las referencias y peso de los distintos tipos de productos.

\begin{tabular}{|c|c|c|c|c|c|}
\hline Referencia & Primera & Segunda & Segunda & $\begin{array}{c}\text { Peso } \\
\text { Unitaria } \\
(\mathbf{K g})\end{array}$ & $\begin{array}{c}\text { Peso } \\
\text { Total } \\
(\text { Kg) } \\
\end{array}$ \\
\hline$\# 3$ & 710 & 10 & $1,39 \%$ & 4,24 & 3010,4 \\
\hline$\# 4$ & 21.740 & 2.870 & $11,66 \%$ & 5,00 & 108700 \\
\hline$\# 5$ & 985 & 130 & $11,66 \%$ & 6,47 & 6372,9 \\
\hline$\# 6$ & 210 & 10 & $4,55 \%$ & 7,69 & 1614,9 \\
\hline$\# 7$ & 58 & 592 & $91,08 \%$ & 8,40 & 487,2 \\
\hline \multirow[t]{3}{*}{$\# 3$} & 710 & 10 & $1,39 \%$ & 4,24 & 3010,4 \\
\hline & & & & TOTAL & 120185,5 \\
\hline & & & & $\begin{array}{c}\text { Equivalente } \\
\text { en ref } 4\end{array}$ & 24037,91 \\
\hline
\end{tabular}

Tabla 1. Ejemplo de producción diaria, para tener producción equivalente

\section{B. Régimen Productivo de los Secaderos}

En los secaderos el proceso demora entre 20 a 24 horas para luego ser llevado al horno para su posterior cocción. Los secaderos tienen el mismo funcionamiento físico, pero se diferencia en su diseño y capacidad.

El secadero pequeño está compuesto por una pequeña cámara de combustión que funciona a partir de la quema o combustión de carbón, la cual alimenta un stocker que tiene un tornillo sinfín que alimenta la cámara de combustión. Luego un ventilador de manera directa inyecta aire caliente hacia los dos túneles del secadero (cada túnel tiene una longitud de 50 metros), al final de estos se encuentran dos extractores que son los encargados de extraer la humedad cedida por los ladrillos. El secadero es alimentado por un sistema hidráulico encargado del ingreso de las vagonetas (introduce una vagoneta y saca una vagoneta), las cuales se encuentran sobre un sistema de rieles. En el exterior del secadero hay un carril de retorno el cual es empujado manualmente.

El secadero grande está compuesto por una cámara de combustión que funciona a carbón, y luego dos ventiladores suministran aire caliente de manera directa a dos pequeños túneles llamados tiros, que alimentan a dos cámaras túnel las 
cuales tienen cada una un par de hileras de vagonetas, los tiros tiene unas válvulas que son las encargadas de suministrar el aire caliente a las dos cámaras. Las cámaras túnel tienen divididos por cuatro (4) juegos de ventiladores llamados recirculadores; al final de cada cámara túnel hay un extractor. El sistema de alimentación es un sistema hidráulico el cual inserta una vagoneta y arrastra el resto hasta poner una a la salida en el otro extremo. Este cuenta con 138 vagonetas que son estilo estantería y tienen una capacidad de 300 unidades equivalentes a referencia \#4. Las cámaras túnel tienen una capacidad de 32 vagonetas y una longitud de 70 metros, para un total de 128 vagonetas repartidas en 4 hileras, y 10 que se encuentran fuera del secadero como reserva, la capacidad de carga máxima por unidad es de 38400 ladrillos.

C. Estudio de Energía Eléctrica de los Secaderos

La realización de mediciones de campo tiene como propósito:

Complementar los datos recopilados del secadero, a manera de respaldo técnico en áreas donde la información no está disponible.

Reconocer la operación de los equipos primordiales, obteniendo una plataforma para las estimaciones de ahorro y aportando un perfil de la eficiencia del secadero.

Complementar la elaboración del estudio de energía eléctrica del secadero comparándolo con el global de la planta, en donde intervienen diferentes equipos eléctricos que demandan energía.

D. Levantamiento de Motores

Principalmente la energía eléctrica demandada en la ladrillera está dada por el uso de Motores. Motores A.C de diferentes potencias que oscilan entre $1 \mathrm{HP}$ y $50 \mathrm{HP}$.

Los motores de mayor potencia se utilizan en los impulsores encargados de ventilar el aire dentro del secadero. Un ejemplo del levantamiento de los motores del secadero se consolida en la Tabla 2.

La eficiencia que se muestra en la tabla 3, es el valor marcado en la placa del motor o documentos del fabricante del equipo. Esta eficiencia está dada para la operación del motor a plena carga.
Como se puede apreciar en la Figura 7, el mayor consumo de energía eléctrica se encuentra en la ventilación y extracción, como es común en cualquier secadero. El motor de mayor capacidad y por ende de mayor consumo es el del tiro 1, el cual es el encargado de suministrar el aire caliente hacia los dos túneles de secado, consumiendo de esta manera más del $50 \%$ del total de energía eléctrica en el secadero pequeño.

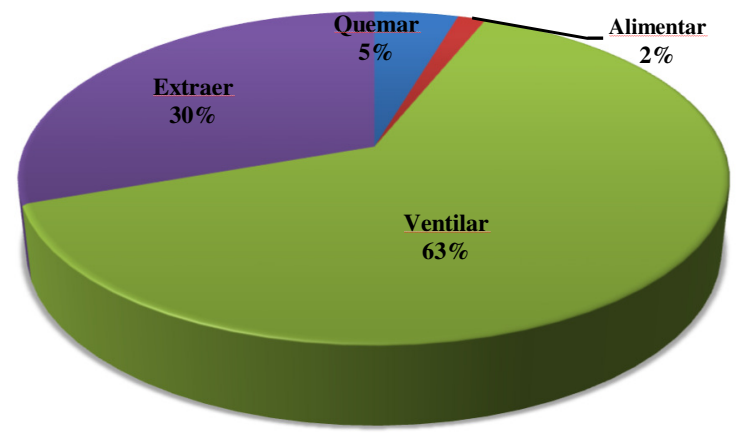

Figura 7. Consumo en el secadero pequeño por actividad. En el secadero grande se da también por el sub-proceso de ventilación, consumiendo el 54\% del total de energía eléctrica que este gasta, Figura 8. A diferencia del secadero pequeño en este se encuentran dos motores de una capacidad de 48HP.

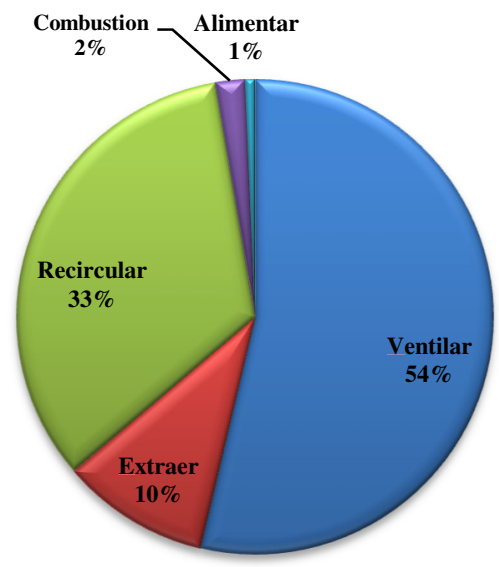

Figura 8. Consumo en el secadero por actividad grande.

\begin{tabular}{|c|c|c|c|c|c|c|c|c|}
\hline Nomenclatura & $\begin{array}{c}\text { Potencia } \\
(\text { Hp) }\end{array}$ & RPM & Servicio & $\begin{array}{c}\text { Consumo diario de } \\
\text { potencia/ HP }\end{array}$ & $\begin{array}{l}\text { Consumo/ } \\
\text { Hora }(W) \\
\end{array}$ & $\begin{array}{c}\text { Eficiencia } \\
80 \% \\
\end{array}$ & $\begin{array}{c}\text { Horas de } \\
\text { trabajo }\end{array}$ & $\begin{array}{c}\begin{array}{c}\text { Consumo por } \\
\text { día }\end{array} \\
\end{array}$ \\
\hline Ventilador de tiro canal 1 & 18 & 1700 & continuo & 18 & 13428 & 10742,4 & 12 & 128908,8 \\
\hline Ventilador de tiro canal 2 & 18 & 1700 & continuo & 18 & 13428 & 10742,4 & 12 & 128908,8 \\
\hline Impulsión canal 1 & 48 & 1700 & continuo & 48 & 35808 & 28646,4 & 24 & 687513,6 \\
\hline Impulsión canal 2 & 48 & 1700 & continuo & 48 & 35808 & 28646,4 & 24 & 687513,6 \\
\hline Stocker & 1,8 & 1400 & continuo & 1,8 & 1343 & 1074,24 & 24 & 25781,76 \\
\hline Ventl. Stocker & 1,8 & 1122 & continuo & 1,8 & 1343 & 1074,24 & 24 & 25781,76 \\
\hline $\begin{array}{l}\text { Impulsor carretilla } \\
\text { entrada secadero }\end{array}$ & 1 & 1700 & $\begin{array}{l}\text { intermi- } \\
\text { tente }\end{array}$ & 4,8 & 3581 & 2864,64 & 6 & 17187,84 \\
\hline 20 Recirculadores & 3 & 650 & continuo & 60 & 44760 & 35808 & 24 & 859392 \\
\hline & & & & & & & \multicolumn{2}{|c|}{2560988,16} \\
\hline \multicolumn{6}{|c|}{ Valor del KW } & $\$ 284,50$ & & $2561 \mathrm{KW}$ \\
\hline & osto Energé & ico dial & o del secac & ero grande & & \multicolumn{3}{|c|}{$\$ 728604,50$} \\
\hline
\end{tabular}

Tabla 2. Listado de motores secadero 
El siguiente subproceso de mayor consumo está dado por la recirculación, ya que en este diseño un $33 \%$ de la energía es utilizada para la recirculación del aire caliente, para así crear un flujo turbulento dentro del secadero para garantizar un secado más uniforme dentro del secadero.

\section{E. Consumo Eléctrico del Proceso de Secado en Cada Secadero}

Como se puede observar en la Figura 9, en el total del consumo eléctrico del proceso secado un $69 \%$ es del secadero grande, lo que es de esperarse ya que este es mucho más grande e invierte mucho más trabajo en recircular el aire dentro del secadero, mientras que el secadero pequeño consume el $31 \%$ del total de energía que se invierte en el secado.

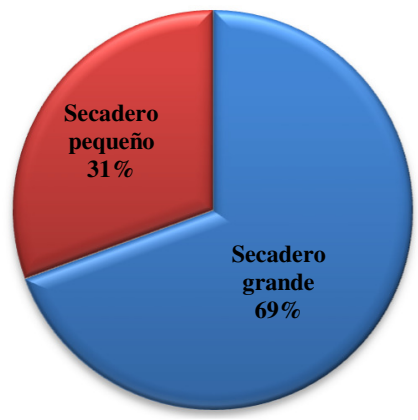

Figura 9. Consumo eléctrico procesos de secado.

Apoyándose en las figuras anteriores se puede concluir que el consumo de energía eléctrica no es proporcional al rendimiento de los secaderos ya que estos están produciendo la misma cantidad de piezas diarias, generándose de esta manera un mal manejo operativo en el secadero grande. Lo cual da pie para proseguir con nuestro estudio energético.

\section{F. Consumo de Energía Eléctrica de la Planta versus el Proceso de Secado.}

En la Figura 10 se puede observar, que el consumo eléctrico global de los secaderos en comparación con la planta tan solo es el 23\% del total, teniendo mayores gastos eléctricos en los procesos de extrusión y preparación de material, con una mayor cantidad de motores y de mayor capacidad; mas sin embargo a pesar de que en los secaderos no se da un gran impacto en el consumo eléctrico, hemos visto que el manejo en este procesos tiene muchas falencias, llevando este procesos de manera ineficiente, desde todo punto de vista.

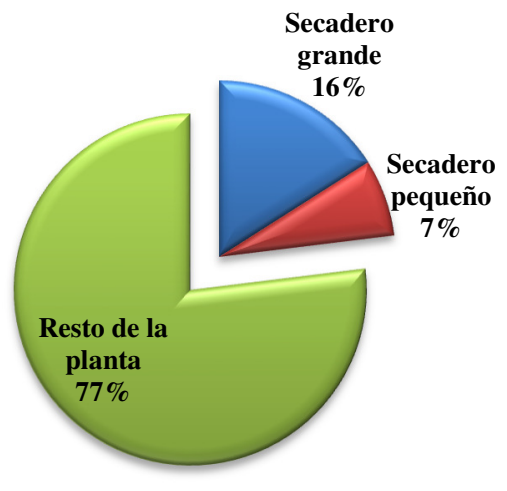

Figura 10. Consumo eléctrico planta vs proceso de secado.

\section{G. Consumo de Carbon en el Proceso de Secado.}

El sistema de alimentación de las cámaras de combustión son llamados stocker, estos son sencillamente una tolva la cual alimenta un tornillo sinfín, que a su vez termina en las rejillas de la cámara de combustión.

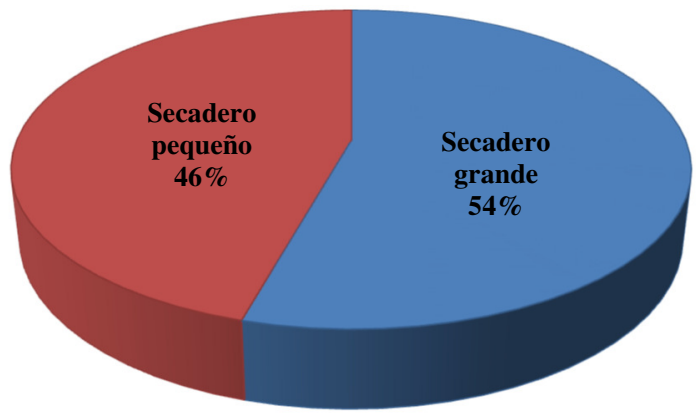

Figura 11. Consumo carbón en los Secaderos.

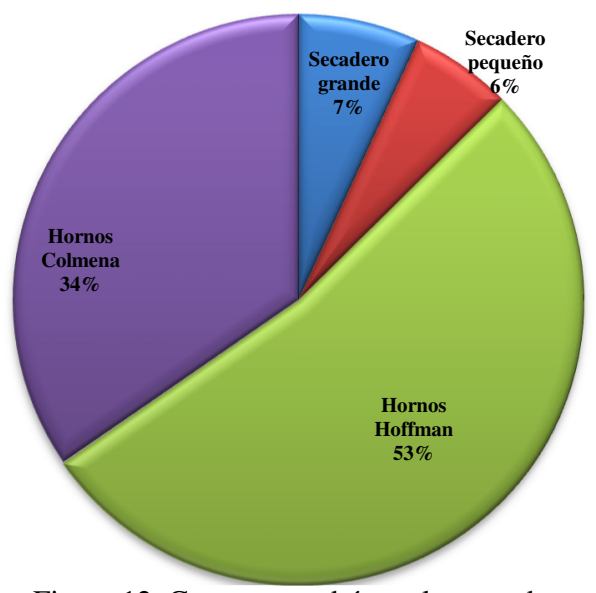

Figura 12. Consumo carbón en los secaderos.

De la Figura 11 se puede concluir que el consumo de carbón entre los secaderos es prácticamente el mismo, lo que concuerda con el nivel de producción de estos.

El consumo de los dos secaderos es el $13 \%$ de la planta. Figura 12, ya que las temperaturas que se manejan en el secado son mucho menores a las que se trabajan en los hornos, y además de que la temperatura en el proceso de secado debe ser correctamente controlada, ya que si esta llega a superar los $100^{\circ} \mathrm{C}$ el material tiende a romperse.

\section{H. Gastos Diarios de Produccion en el Proceso de Secado}

De las Tablas 3 y 4, se puede observar el costo por kilogramo de material secado y hacer la comparación entre los secaderos, notando que secar un kilogramo en el secadero grande es mucho más costoso, que secarlo en el secadero pequeño. 


\begin{tabular}{|c|c|c|}
\hline GASTOS POR SECADO, SECADERO PEQUEÑO & \\
\hline Ítem & valor por día & \\
\hline Carbón & $\$ 233.853$ & \\
\hline Personal & $\$ 196.828$ & \\
\hline Energía eléctrica & $\$ 335.766$ & \\
\hline Mantenimiento & $\$ 63.013$ & \\
\hline TOTAL & \$ 829.460 & \\
\hline Promedio de Kg secado por día & 39952 \\
\hline VALOR DEL SECADO POR KG DE MATERIAL & \$ 20,76 \\
\hline \multicolumn{2}{|c|}{ Tabla 3. Gastos en el secadero pequeño } \\
\end{tabular}

Tabla 3. Gastos en el secadero pequeño

\begin{tabular}{|c|c|c|}
\hline \multicolumn{2}{|c|}{ GASTOS POR SECADO, SECADERO GRANDE } & \\
\hline Ítem & valor por día & \\
\hline Carbón & $\$ 277853,0$ & \\
\hline Personal & $\$ 108290,0$ & \\
\hline Energía eléctrica & $\$ 728604,50$ & \\
\hline Mantenimiento & $\$ 63013,0$ & \\
\hline TOTAL & $\$ 1177760,50$ & \\
\hline \multicolumn{2}{|c|}{ Promedio de Kg secado por día } & 41745 \\
\hline \multicolumn{2}{|c|}{ VALOR DEL SECADO POR KG DE MATERIAL } & $\$ 28,21$ \\
\hline
\end{tabular}

Tabla 4. Gastos en el secadero grande

Sin embargo, esto no indica la calidad de dicho proceso, es decir, que no se tiene la certeza de que se está secando de la manera que debe ser, es por eso que se debe tener en cuenta ademas la humedad residual en cada producto, para asî determinar qué tan eficiente está siendo estos procesos de secado, y de esta manera tomar una decisión clara acerca de las medidas a tomar en el proceso [11].

\section{Humedad Residual o Humedad Admisible}

La humedad admisible es aquella que tiene el producto después de pasar por el proceso de secado, para ser ingresados a los hornos. Esta humedad está condicionada directamente al horno a donde el producto va a ser quemado, además de las condiciones propias de operación que se le dan al producto en la empresa. Para tener una idea más clara acerca de la humedad admisible, hay que profundizar un poco en el funcionamiento de los hornos Hoffman que son los utilizados en la empresa ladrillera barranquilla LTDA.

En los Hornos Hoffman la cocción se desplazaba por las secciones de forma secuencial, mientras en una sección se estaba cociendo el material, en la siguiente se empieza a elevar la temperatura y va absorbiendo humedad terminando de secar el material. La cantidad de humedad que extrae el horno depende del tipo de material (geometría del material) y la forma del apilado (disposicion de los ladrillos) dentro de las cámaras conocido en el medio como "encañe".

A partir de estudios previos y de acuerdo con los hábitos operacionales, la humedad admisible para los hornos en Ladrillera Barranquilla es del 5\%. Teniendo en cuenta lo anterior y basado en los estudios de desperdicios, consumos energéticos y ratas de producción, se decidio hacer pruebas en laboratorio para así tener claro que tan bien se está secando el producto y si esta humedad admisible es correspondiente con el porcentaje permitido en las normas de la empresa.

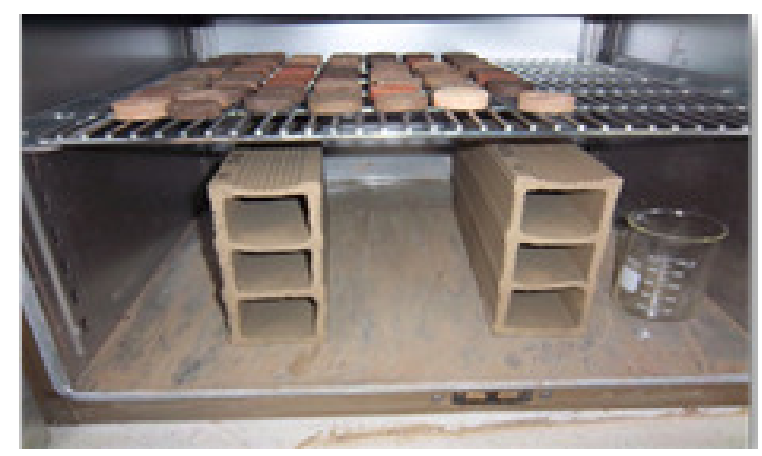

Figura 13. Mufla de secado.

Para determinar el nivel de humedad con el que sale el material del secadero, en la planta se encuentra una mufla de secado, Figura 13. Para realizar las pruebas el material se tomaba y era pesado, luego se introducía en la mufla de secado durante 24 horas, para retirarle cualquier rastro de humedad, para luego ser pesado otra vez y tomar la diferencia de estos pesos y así poder determinar la cantidad de agua que poseía el material y por consiguiente el porcentaje de humedad.

Estas medidas se realizaban tres veces al día, una al inicio del proceso, a mediados de este y al final del secado. Estas medidas se tomaban de ambos secaderos durante el periodo en que se realizó el estudio. Las muestras se tomaban en distintos puntos de las vagonetas, para así también determinar qué tan uniforme era el secado del material, Figura14.

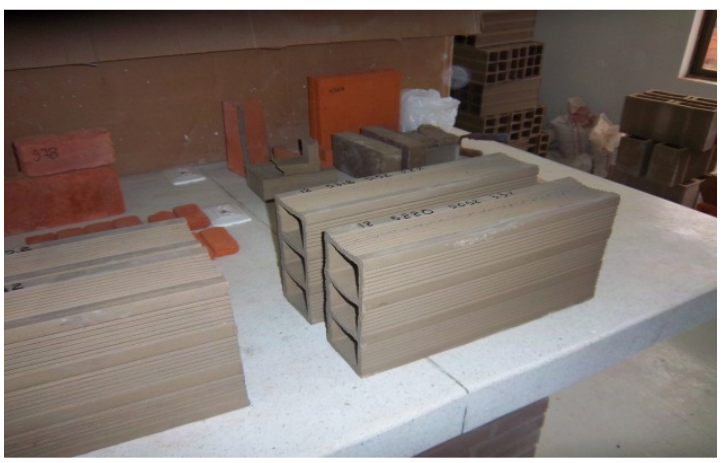

Figura 14. Muestras del secadero

A continuación se muestran las gráficas de porcentaje de humedad residual del material, Figura 15.

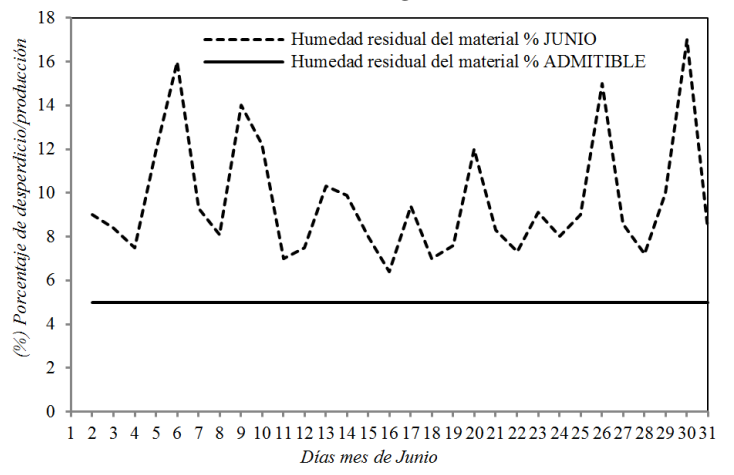

Figura 15. Humedad residual del material mes de Junio Secadero pequeño. 


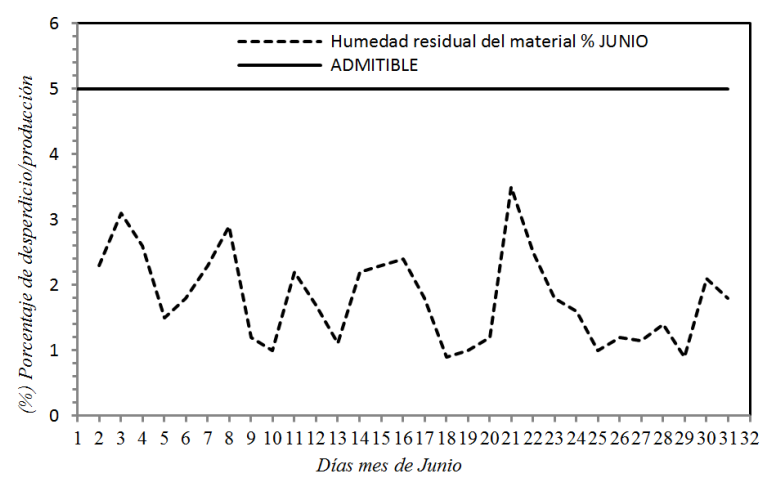

Figura 16. Humedad residual del material mes de Junio Secadero grande.

En el estudio realizado para determinar las humedades residuales del material se observa que para el secadero pequeño la humedad admisible se encuentra muy por encima, mientras que en el secadero grande se encuentra bastante por debajo, generándose de esta forma gran cantidad de material de desperdicio a la salida del horno.

Es importante decir que las muestras tomadas en el secadero pequeño arrojan que el secado en este no se da de manera uniforme, ya que el material tomado del centro de la vagoneta contenía mucho más humedad que el material contenido en el exterior de la vagoneta, lo que no pasa en el secadero grande, el cual si seca de manera uniforme el material sin importar su ubicación en la vagoneta, este secado uniforme en el secadero grande se debe a la presencia de los recirculadores, parte vital en el diseño y eficiencia de este tipo de secaderos.

\section{MEJORAS EN EL PROCESO}

Como se ha podido observar en las graficas, el secadero grande realiza un mejor secado por lo cual se ha decidio en conjunto con los ingenieros de la platan utilizar en adelante unicamente el secadero grande. Los motivos de seguir evaluando el proceso de secado en el secadero grande son los de mejor tecnología, capacidad, y mejor secado. En esta direccion al lograr el objetivo de este estudio estaríamos garantizando la cocción de los ladrillos y disminuyendo de esta manera el desperdicio de producto.

El principal interrogante de la gerencia era el del comportamiento de producción, debido a que se está dejando de utilizar un secadero. Sin embargo, cabe resaltar que el secadero grande no se estaba usando a su capacidad total.

En la Tabla 5, se observa el número de vagonetas por día y kilogramo de material secado en los meses de julio, agosto y septiembre, se nota un incremento progresivo, que es aún más notable en el mes de septiembre en el cual ya se estaba secando mucho más material que cuando se tenían los dos secaderos funcionando.

\begin{tabular}{|c|c|c|c|}
\hline \multicolumn{4}{|c|}{ MATERIAL SECADO Kg } \\
\hline DIA & JULIO & AGOSTO & SEPTIEMBRE \\
\hline 1 & 54450 & 66000 & 85800 \\
\hline 2 & 33000 & 90750 & 77550 \\
\hline 3 & 36300 & 92400 & 75900 \\
\hline 4 & 42900 & 103950 & 70950 \\
\hline 5 & 92400 & 99000 & 107250 \\
\hline 6 & 74250 & 72600 & 70950 \\
\hline 7 & 100650 & 102300 & 95700 \\
\hline 8 & 80850 & 51150 & 74250 \\
\hline 9 & 52800 & 95700 & 90750 \\
\hline 10 & 117150 & 79200 & 92400 \\
\hline 11 & 72600 & 85800 & 99000 \\
\hline 12 & 92400 & 90750 & 92400 \\
\hline 13 & 90750 & 74250 & 80850 \\
\hline 14 & 82500 & 42900 & 92400 \\
\hline 15 & 79200 & 95700 & 107250 \\
\hline 16 & 90750 & 80850 & 113850 \\
\hline 17 & 84150 & 92400 & 82500 \\
\hline 18 & 92400 & 69300 & 90750 \\
\hline 19 & 72600 & 85800 & 94050 \\
\hline 20 & 103950 & 62700 & 99000 \\
\hline 21 & 90750 & 82500 & 94050 \\
\hline 22 & 52800 & 74250 & 122100 \\
\hline 23 & 90750 & 97350 & 90750 \\
\hline 24 & 67650 & 67650 & 107250 \\
\hline 25 & 115500 & 75900 & 103950 \\
\hline 26 & 66000 & 46200 & 95700 \\
\hline 27 & 92400 & 77550 & 97350 \\
\hline 28 & 72600 & 89100 & 102300 \\
\hline 29 & 67650 & 46200 & 105600 \\
\hline 30 & 99000 & 105600 & 99000 \\
\hline 31 & 67650 & 82500 & \\
\hline Promedio & 78348,3871 & 79945,1613 & 93720 \\
\hline Ref. \#4 & 15669,6774 & 15989,0323 & 18744 \\
\hline
\end{tabular}

Tabla 5. Kilogramos de material secado en los meses en donde se ejecuta la medida

En la Figura 17, se presenta el promedio de los kilogramos de material secado artificialmente en el mes de junio $75000 \mathrm{Kg}$ (2 secaderos), y se considera que como mínimo se debe mantener la misma producción en el mes de julio, (1 secadero).

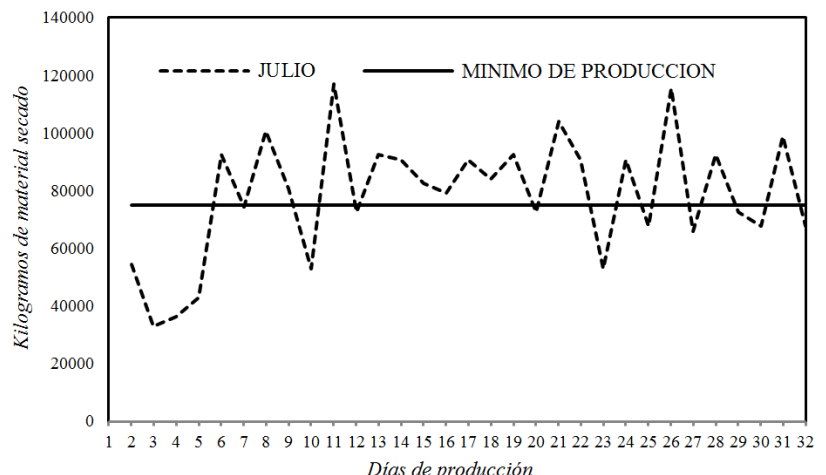

Figura 17. Kilogramos de material secado en el mes de julio versus el mínimo de producción.

Al comparar la producción del mes de julio del secadero grande, con la producción en ambos secaderos en el mes de junio, se nota que la producción comparando el promediode la Tabla 4, con el promediode las Tablas 3 y 4.

En la Figura 17, nada más se muestra el mes de julio, ya que lo que se quiere evidenciar más que el aumento de la producción es que al realizar el cambio, la producción no se 
vio disminuida en ningún momento, al contrario tiende a aumentar, lo cual se hará aún más evidente en los meses venideros.

En la Figura 18, se puede apreciar en la curva del mes de junio picos que están en 0 vagonetas por día, lo cual indica que se realizaba mantenimiento interrumpiendo la producción en este secadero, al mirar la curva de septiembre notamos que no hay picos que estén en 0 , lo cual no quiere decir que no se estén realizando los mantenimientos, sino que estos se llevan a cabo sin tener que interrumpir la producción.

Como se aprecia en la Figura 18, en el mes de septiembre ya se nota un incremento de más del $120 \%$, tomando como referencia el promedio de vagonetas en estos meses para el secadero grande (promedio del mes de junio 25.3 y promedio mes de septiembre 56,8), lo cual se aprecia mucho mejor en la siguiente figura.

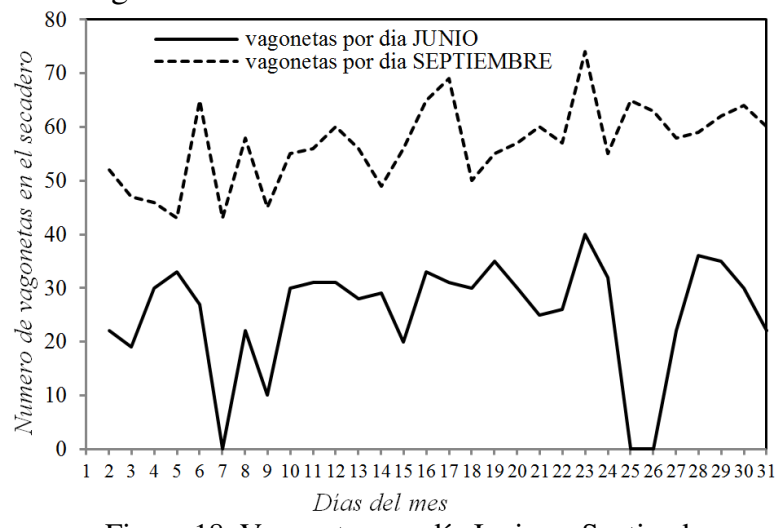

Figura 18. Vagonetas por día Junio vs Septiembre.

Y si se realiza el mismo análisis pero teniendo como referencia los kilogramos de material secado, además de tomar el promedio de piezas teniendo como referencia el ladrillo \#4 se nota el mismo incremento de más del $120 \%$ considerando la producción en el secadero grande, y un incremento en el total de material secado artificialmente ya que este era de $75000 \mathrm{~kg}$ y en el mes de septiembre es de 93700, lo cual se apreciara mejor en la Figura 19, donde se muestran los kilogramos de material secado en el mes de septiembre versus el mínimo que se tenía en la empresa.

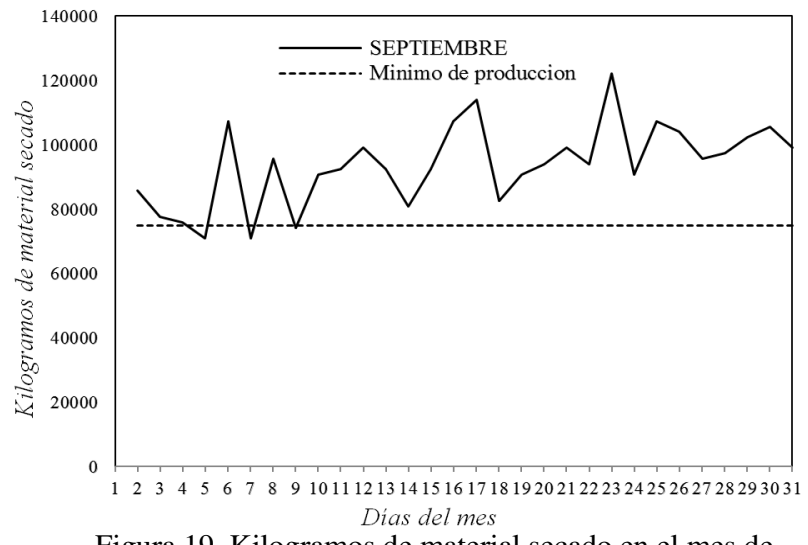

Figura 19. Kilogramos de material secado en el mes de septiembre vs mínimo de producción.
A partir de la figura anterior se puede concluir que el material secado en el secadero artificial ha aumentado considerablemente, dando como resultado un incremento en el proceso de secado y la producción de ladrillos, al remitirnos a la Figura 5, donde se presenta el porcentaje de material secado artificialmente versus el porcentaje de material secado naturalmente, se nota que el secado artificial es solo el 53\%, a partir de la medida tomada por nosotros el secado artificial es el $70 \%$, lo que demuestra mayor control en el proceso de secado, asegurando de esta manera las condiciones del proceso.

Esto mejora se puede observar en la Figura 20, donde se muestra la cantidad de piezas secadas de las dos maneras (artificial y natural).

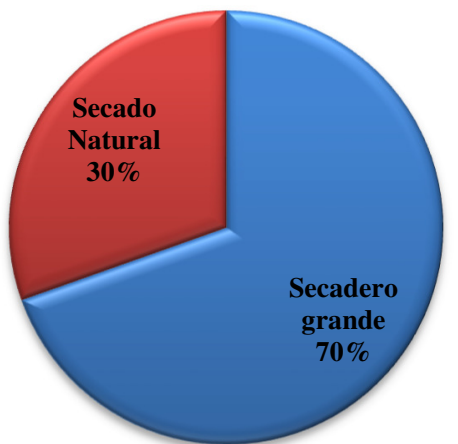

Figura 20. Secado artificial vs secado natural.

Al tener más material secado de manera artificial, lo primera conclusión es que los consumos energéticos deberían aumentar, para ser correspondientes con la producción actual, mas sin embargo, esto no se refleja en los consumos de carbón en comparación con los que se venían dando en el mes de junio, como lo podemos observar en la siguiente Figura 21.

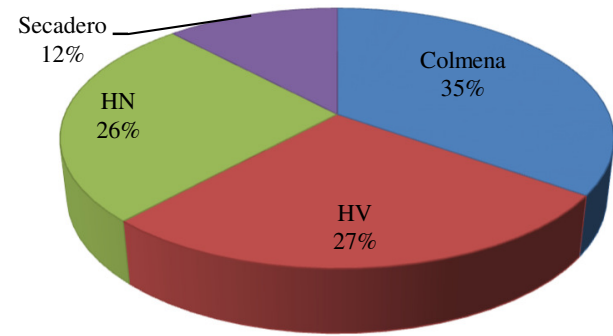

Figura 21. Consumo de carbón por procesos en el mes de Septiembre.

Comparando la Figura 21, con la Figura 11, en donde se muestra el consumo de carbón en el mes de junio se nota que el consumo de carbón no solo no ha aumentado sino que tiene una decremento del $1 \%$ el cual es bastante significativo desde el punto de vista económico. Esto se debe a que el consumo de kilogramos de carbón por el secadero grande es más constante que cuando se tenían los dos secaderos en funcionamiento, Lo cual se puede apreciar mejor a partir de la Figura 22. 


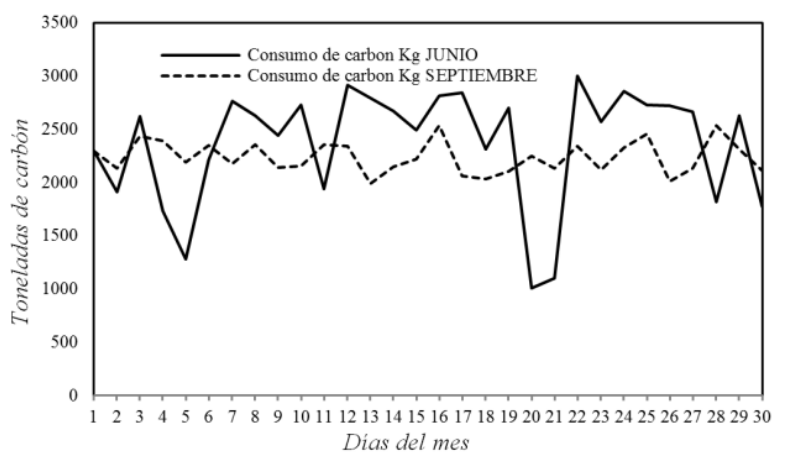

Figura 22. Consumo de kg de carbón mes de Junio vs mes de

Septiembre.

En cuanto al consumo eléctrico en el proceso de secado, la disminución es aún más notable debido a que se esta dejando de utilizar un equipo que es el secadero pequeño, y como se aprecia en la Tabla 2, el listado de motores del secadero grande, la función de la mayoría de estos era continuo, el único aumento sería en el gato hidráulico, el cual es mínimo para generar un impacto considerable.

La Figura 23 muestra el porcentaje del consumo energético que se da en el proceso de secado ahora versus, el consumo de la planta.

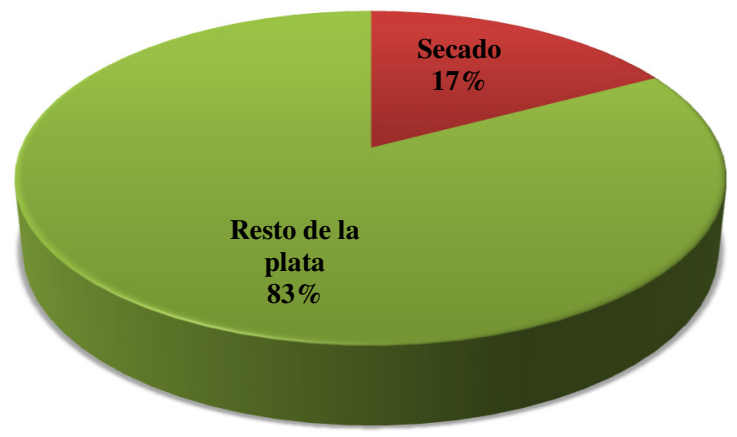

Figura 23. Consumo de carbón de la planta en el mes de Septiembre.

Comparando esta figura con la Figura 10, se nota que el consumo de energía eléctrica en el proceso de secado disminuyo en un $6 \%$, al decidir dejar de utilizar el secadero pequeño y utilizar nada más el secadero grande considerando su eficiencia y capacidad.

Ahora que el consumo de energía eléctrica y de carbón ha disminuido se puede afirmar que existe un ahorro considerable en el precio del ladrillo, pero al tener un solo secadero funcionando la mano de obra en este debe aumentar, además de los costos de mantenimiento, estos costes de mantenimiento aumentan ya que antes se programaba el mantenimiento mientras que ahora son mantenimientos correctivos, los cuales se realizan en lo posible sin tener que detener el proceso de secado, por esto hay un ligero aumento en el presupuesto para repuestos

Ahora bien, sabiendo los diferentes consumos de las energías que intervienen en el proceso de secado, es necesario saber cuánto se esta gastando al secar un kilogramo de material ahora, Tabla 6.

\begin{tabular}{|c|c|c|}
\hline ITEM & \multicolumn{2}{|c|}{ VALOR POR DIA } \\
\hline Carbón & \multicolumn{2}{|c|}{$\$ 469853,0$} \\
\hline Personal & \multicolumn{2}{|c|}{$\$ 249471,438$} \\
\hline Energía eléctrica & \multicolumn{2}{|c|}{$\$ 728604,50$} \\
\hline Mantenimiento & \multicolumn{2}{|c|}{$\$ 80.000,00$} \\
\hline \multicolumn{2}{|l|}{ TOTAL DIA } & $\$ 1527928,938$ \\
\hline \multicolumn{2}{|c|}{$\begin{array}{l}\text { PROMEDIO DE MATERIAL } \\
\text { SECADO POR DIA }\end{array}$} & 79945 \\
\hline \multicolumn{2}{|c|}{$\begin{array}{c}\text { VALOR DEL SECADO / Kg de } \\
\text { material SECADO }\end{array}$} & 19,11225139 \\
\hline
\end{tabular}

Si comparamos el costo de secar un kilogramo ahora mostrado en la Tabla 6, con el costo de secar un kilogramo antes el cual podemos observar en las Tablas 3 y 4, al realizar un simple cálculo podemos determinar que el ahorro generado es de $\$ 403.000$ pesos (cuatrocientos tres mil pesos) diarios, un ahorro al mes de $\$ 12.000 .000$ pesos (doce millones de pesos), nada más para el proceso de secado sin tener en cuenta la reducción en desperdicio.

La disminución de desperdicio también fue evidente después de tomar la medida, y realizar la evaluación energética, esto se puede observar mejor en la Figura 24, que nos muestra el desperdicio en el mes de septiembre versus el admisible que es de un $10 \%$.

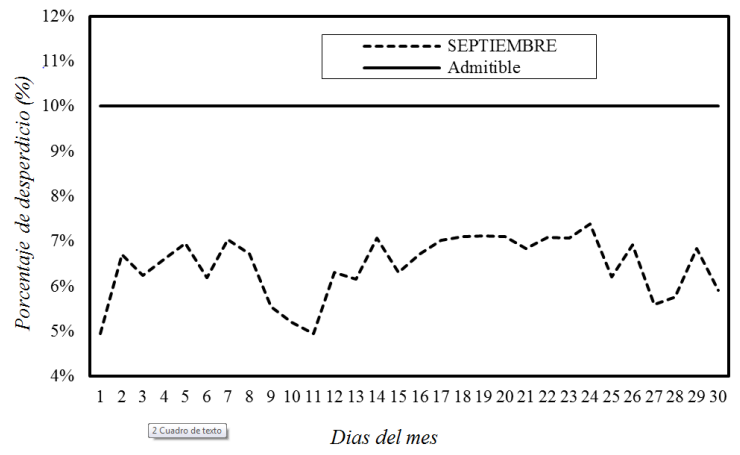

Figura 24. Porcentaje de desperdicio de la planta en el mes de Septiembre.

Al comparar el porcentaje de desperdicio en el mes de Septiembre con el mes de Junio se nota la gran diferencia y disminución que se ha logrado en este ítem en la producción total de la empresa, ya que como se sabe el desperdicio se determina al salir del horno, pero el secado es el que garantiza la disminución del desperdicio.

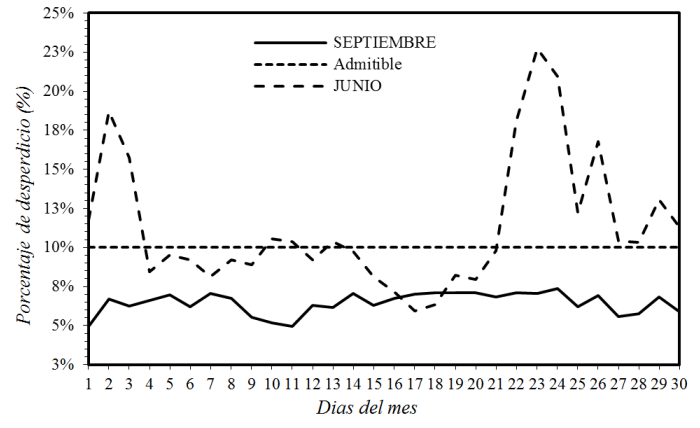

Figura 25. Porcentaje de desperdicio de la planta en el mes de Junio vs Septiembre. 
Como se puede observar en la Figura 25, el porcentaje en el mes de septiembre se encuentra por debajo del admisible por la empresa, mientras que en el mes de junio muestra varios picos mayores al $15 \%$ y unos mayores al $20 \%$, lo cual muestra un mal control del proceso de secado.

El ahorro que se da a partir del mejoramiento en el proceso de secado, y por ende disminución de las unidades de desperdicio se puede apreciar en la siguiente tabla.

\begin{tabular}{|c|c|c|}
\hline & Junio & Septiembre \\
\hline $\begin{array}{c}\text { Promedio desperdicio } \\
\text { mes en unidades }\end{array}$ & 2841 & 1719 \\
\hline Costo de ladrillo & $\$ 880,00$ & $\$ 880,00$ \\
\hline Total en pesos & $\$ 2.500 .080,00$ & $\$ 1.512 .720,00$ \\
\hline Ahorro diario & $\$ 987.360,00$ & \multicolumn{1}{|}{} \\
\hline Ahorro mensual & $\$ 29.620 .800,00$ & \multicolumn{1}{|l}{}
\end{tabular}

Tabla 7. Costo del proceso de secado por kilogramo de material secado

El ahorro como se observa es bastante alto y al tomar este ahorro con el que anteriormente se mostraba que se dio en el proceso de secado como tal, da un gran total de $\$ 41.500 .000$ de pesos (cuarenta y un millones quinientos mil pesos) mensuales. Todo esto gracias a la regularidad a la que entra el material a los hornos.

Al garantizar el proceso de secado, se disminuye notablemente el desperdicio a la salida de los hornos, para garantizar el proceso se debe controlar la humedad residual del material a la salida del secadero.

En la Figura 26 se muestra el comportamiento de la humedad residual en el mes de septiembre versus el admisible.

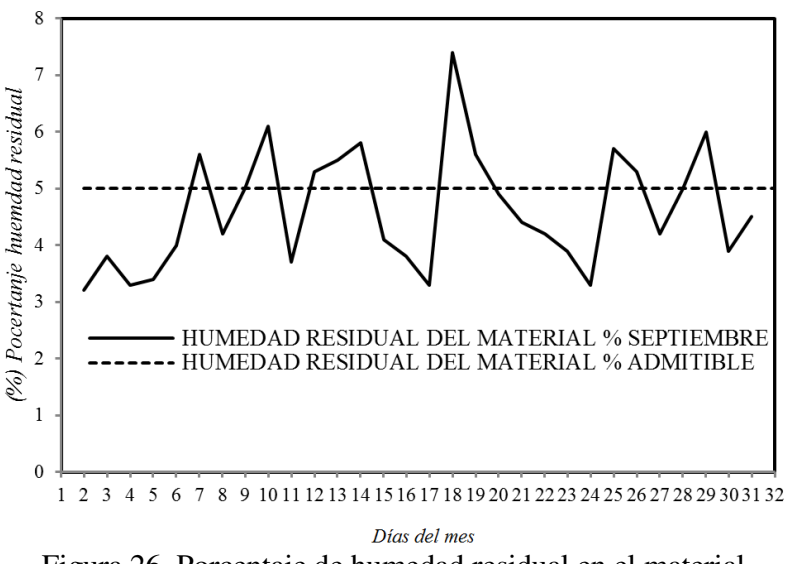

Figura 26. Porcentaje de humedad residual en el material.

En la Figura 26 se observan algunos picos, mas sin embargo la curva no está alejada de la humedad residual admisible, y si se considera el desempeño del mes tenemos que el promedio de humedad residual en el mes de septiembre es del $4.6 \%$, el cual muestra un secado optimo, que garantiza el proceso de producción.

A continuación se muestra en la Figura 27, la humedad residual en el mes de Junio versus el mes de Septiembre.

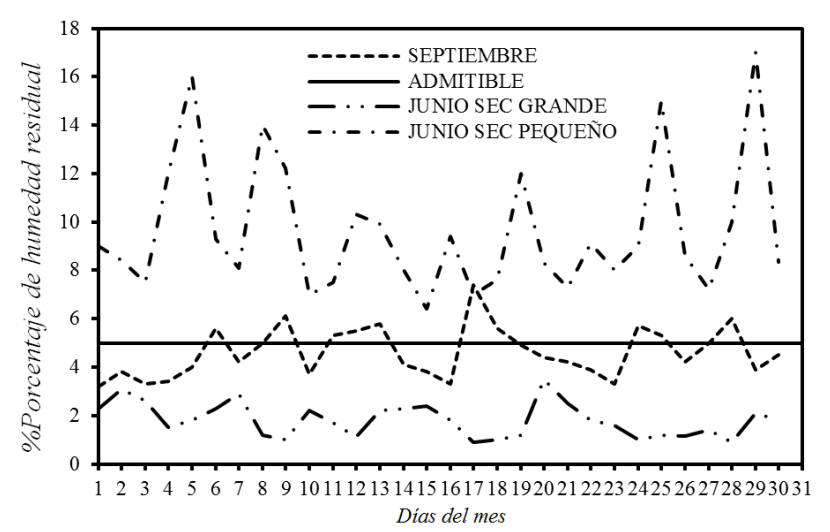

Figura 27. Comparación humedad relativa del proceso

En la Figura 27 se puede observar, las curvas de humedad residual en el mes de septiembre versus las de junio comparadas con el admisible por la empresa, en el mes de junio se observan dos curvas debido a que se realizaba la producción en dos secaderos como ya se describió entes, en el secadero pequeño la curva siempre se encuentra por arriba del admisible y en el secadero grande muy por debajo de este.

Se aprecia que al tener un solo secadero en funcionamiento se controla mejor el proceso y se mejora en todo punto de vista de este.

En esta Tabla 8, se observa con mayor detalle el impacto del cambio que se realizó en la planta que fue mucho más de lo esperado.

\begin{tabular}{|l|r|r|}
\hline PROCESO DE SECADO / ÍTEM & \multicolumn{1}{|c|}{ JUNIO } & SEPTIEMBRE \\
\hline Producción & 15670 unid. & 18744 unid. \\
\hline kg material secado artificialmente & $53 \%$ & $70 \%$ \\
\hline Consumo de carbón vs planta & $13 \%$ & $12 \%$ \\
\hline Consumo eléctrico vs planta & $23 \%$ & $17 \%$ \\
\hline Costos mano de obra por día & $\$ 359.265,00$ & $\$ 249.471,00$ \\
\hline Costos mantenimiento diario & $\$ 63.000,00$ & $\$ 80.000,00$ \\
\hline Costo de secado del ladrillo & $\$ 122,00$ & $\$ 96,00$ \\
\hline$\%$ Desperdicio & 2841 unid. & 1719 unid. \\
\hline Costo desperdicio diario & $\$ 2.500 .080,00$ & $\$ 1.512 .720,00$ \\
\hline$\%$ Humedad residual & $11,31 \%$ & $4,60 \%$ \\
\hline
\end{tabular}

Tabla 8. Cuadro comparativo del proceso de secado entre el mes de Junio y Septiembre

Además de aumentar la cantidad de material secado artificial se disminuyó el costo del secado, además de la disminución del precio del secado por ladrillo, y la regularidad de la humedad residual lo que mejora la calidad del ladrillo, todo esto llevando un control de los parámetros y llevando el secadero a un máximo poder de trabajo.

Cabe decir que no solo se generan mayores ganancias a partir de este nuevo régimen de producción sino que además al comparar con el régimen anterior se está dando un ahorro monetario de aproximadamente $\$ 42.000 .000$ de pesos (Cuarenta y dos millones de pesos) mensuales, este calculado en el mes de septiembre. 
Si se considera la tendencia a mejorar que se ha mostrado en el proceso, dará aún más beneficios. Esto claro, está regido a que se siga llevando el proceso como se está llevando, por esto se dan algunas recomendaciones para seguir garantizando la mejora continua del proceso de secado.

\section{RECOMENDACIONES PARA EL PROCESO DE SECADO Y PROPUESTAS DE MEJORAS TECNOLOGICAS}

A continuación se plantean una serie de recomendaciones para mantener el control en el comportamiento del proceso de secado actual.

1. Mantener por debajo del $5 \%$ la humedad residual del material que sale del secadero para garantizar su correcta cocción y disminuir el desperdicio.

2. En la medida de lo posible realizar las labores de mantenimiento sin afectar la productividad del secadero.

3. Priorizar el trabajo de los recirculadores, ya que de estos depende la uniformidad del secado.

4. Descargar el material de secadero por zonas (secciones), y no por hileras como se venía realizando.

5. Mantener la humedad de entrada del material al secadero que es de $20 \%$.

6. Mantener la temperatura del secadero entre 70 y $80^{\circ} \mathrm{C}$.

7. El personal que ingresa al secadero, se encuentre capacitado y con los implementos de protección.

8. Tener en el stock de repuestos mínimo 1 pieza de los elementos principales y propensos a fallas en el secadero, para garantizar el mantenimiento.

9. Mantener en buen estado los rieles y rodamientos de las vagonetas.

10. Realizar constante limpieza en los ductos de los tiros.

11. Revisar que los ductos no tenga posibles escapes o infiltraciones.

Algunas mejoras tecnológicas a tener en consideración en el proceso de secado son.

Utilización de Aditivos; el empleo de aditivos tiene por objeto aumentar al máximo la permeabilidad de las piezas para facilitar la migración del agua hacia la superficie.

Recuperación del Calor Sensible de los Humos de Hornos; los gases de combustión de un horno contienen una cierta energía, pues su nivel de temperatura es del orden de $100-140^{\circ} \mathrm{C}$. Es lógico ahorrar costes recuperando parte de esta energía en otras etapas del proceso donde se pueda utilizar. El objetivo es aumentar la eficacia energética global del proceso. Ahora bien, no todo el calor es recuperable, pues depende, entre otras cosas, de la temperatura de salida de los humos, de su contenido de azufre y de la carga del horno.

Utilización de Aislamientos; la utilización de aislamientos en el secadero y en los conductos de gases calientes extraídos del horno mejora notablemente el rendimiento energético con una inversión reducida. El aislamiento es una de las formas más económicas de mejorar el proceso, sin embargo el ahorro es entre el 1 y $2 \%$.

Utilización de Sistemas de Control; el control automático aplicado a un secadero es imprescindible para conseguir un proceso de secado óptimo, que permita obtener una mayor calidad de material, así como una reducción de los costos de fabricación tanto debido al ahorro energético conseguido, como por la reducción de piezas defectuosas. Esta optimización solo se obtendrá si se dispone del sistema de regulación adecuado. Esto quiere decir, que el proceso se realizará en buenas condiciones, cuando el material siga exactamente la curva de secado que se fije según sus características y composición.

Utilización de Secaderos Continuos; los secaderos continuos presentan una serie de ventajas sobre los otros tipos de secaderos. Como por ejemplo, disminución de la mano de obra, aumento de la velocidad de secado, disminución del consumo energético, facilidad de control automático de la humedad y la temperatura, integración óptima con el horno (si el horno es tipo túnel).

Empleo de la Bomba de Calor; mediante la bomba de calor se toma calor de un foco frío (aire templado y húmedo a la salida del secadero) y se cede a un foco caliente (aire que va a utilizarse en el secado).

Mejoras en Distribución de Aire en Secaderos; en los secaderos túnel continuos o semicontinuos, la distribución de aire en el interior se realiza a trasvés de inyección de aire por la parte superior. Para mejorar la distribución de calor se están instalando ventiladores de tipo cónico, que permite regular a lo largo de toda la altura de la estantería la entrada de aire caliente, y por tanto la temperatura de secado. Es decir, permiten homogenizar la temperatura y la humedad en toda la altura del paquete. Se mejora la calidad final del producto y se reduce así el ciclo de secado del equipo con el consiguiente ahorro energético (del orden del 10-20\% del consumo inicial del secadero).

Recirculadores Cónicos; el recirculador cónico es un ventilador helicoidal situado en el techo del secadero en el pasillo entre carretillas. Este ventilador mezcla el aire caliente procedente de la impulsión de aire, con aire húmedo del interior del secadero. Este aire se impulsa a un cono que tiene una ranura a lo largo de toda la generatriz del mismo. El aire sale de esta rendija a una elevada velocidad y por tanto con alta presión entrando este aire hasta el fondo de la carretilla. El cono tiene un movimiento lento de rotación para repartir la mezcla de aire a todo su alrededor. Todos los elementos mecánicos de accionamiento, tanto del cono como del ventilador, están en el exterior del secadero. De este modo no se someten estos elementos a las condiciones de temperatura y humedad del interior del secadero, evitando un mayor desgaste y facilitando su manutención. Incluso el engrase puede hacerse por el exterior.

\section{CONCLUSIONES}

A partir de la evaluación energética que se le realizo al proceso de secado en la Ladrillera Barranquilla LTDA, se mejora el proceso desde todo punto de vista, generando un gran impacto en el proceso de producción como tal y en la economía de la empresa:

Aumento en la producción ya que a partir de la evaluación ahora se dan 18800 unidades diarias, un aumento de 3200 unidades a partir del secado artificial. 
Aumento en la producción en el secado artificial ya que ahora un $70 \%$ de los ladrillos producidos son por medio del secado artificial, lo cual garantiza el proceso, ya que a diferencia del natural acá si tenemos control de las variables, el secado artificial antes de la evaluación era de $53 \%$ aumentado un $17 \%$ después de la evaluación energética.

Se disminuyó el consumo de energía eléctrica y consumo de carbón en el proceso de secado, antes de la evaluación se tenían dos equipos trabajando, después de esta se trabaja con un solo secadero. El consumo de carbón disminuyo en $1 \%$ mientras que el de energía eléctrica en un $6 \%$, generando de esta manera menos gastos, lo cual da un ahorro en la economía de la empresa. Además de esto si consideramos que al tener una sola maquina en trabajo, la mano de obra disminuye también lo cual genero un ahorro de $\$ 110.000$ pesos diarios, y un pequeño aumento en el mantenimiento, ya que se ha cambiado el régimen de producción, que nos genera un aumento de $\$ 17.000$ pesos diarios, considerando toda esta inversión nos genera en el proceso de secado un ahorro de $\$ 12.000 .000$ millones de pesos, en el proceso de secado, sin tener en cuenta los beneficios o ingresos que se generan por el nuevo régimen productivo, ya que se aumentó la rata de producción y se disminuyó la cantidad de desperdicio.

A partir de estos anteriores ahorros en los diferentes consumos del proceso de secado y teniendo en cuenta el aumento en la producción, es obvio deducir que el precio de ladrillo en el proceso de secado disminuye, antes cada ladrillo secado tenía un costo de $\$ 122$ pesos, mientras que después de la evaluación energética el precio del ladrillo es de $\$ 96$ pesos, un ahorro de $\$ 26$ pesos por ladrillo.

Se disminuyó la cantidad de desperdicio de producción, antes de la evaluación el proceso de secado no garantizaba las condiciones para una buena cocción, generando de esta manera grandes cantidades de desperdicio, al día se perdían 2840 unidades, mientras que después de la evaluación este número se redujo a 1720 unidades, una disminución de 1120 unidades diarias, lo cual genera un impacto económico bastante significativo como lo es de $\$ 1.000 .000$ de pesos diarios.

Se garantizó el proceso de cocción mejorando las condiciones para este, ya que en el proceso de secado se controlan las condiciones y de esta manera se disminuyó la humedad residual en los materiales, ya que para garantizar la cocción este debe estar alrededor del 5\% de la humedad residual, antes de la caracterización esta humedad promediaba un 11,3\%, y después de la caracterización se promediaba el 4,6\%, lo cual da pie para una buena cocción.

A partir de los beneficios anteriormente mencionados, generados por la evaluación energética en el proceso de secado el impacto económico que este le generó a la empresa es un ahorro de $\$ 42.000 .000$ millones de pesos mensuales, además de los beneficios cualitativos como lo son la mejor calidad de producto y satisfacción de los empleados y consumidores.

La evaluación energética también incluye un camino más fácil pero costoso que es el de las mejoras tecnológicas, este camino no fue abordado por nosotros con tanta profundidad debido al gran impacto que se generó en el proceso de secado a partir del camino difícil pero económico, mas sin embargo se dan recomendaciones de cómo mejorar aún más el proceso de secado, y que tanto beneficios se pueden generar a partir de estos.
En conclusión la evaluación energética es una gran herramienta para evaluar nuestros procesos, saber lo que se está haciendo y que tan bien es lo que estamos haciendo, ahora más que nunca debido a la gran competitividad industrial y el uso eficiente de la energía como requisito de certificación.

\section{REFERENCIAS}

[1] A. Martinez, A. Valero. "Disminucion de Costes Energeticos en la Empresa, Tecnologias y Estrategias para el Ahorro y la Eficiencia Energetica". Madrid. eEiciones Fundacion Confemetal. 2009. ISBN 84-9616979-0.

[2] Y. Calventus, R. Carreras. "Tecnologia Energética y Medio Ambiente. Barcelona", Ediciones Universidad Politécnica de Cataluña. 2006, Primera Edición. ISBN 84-8301-848-9.

[3] UPME y Colciencias. "Ahorro de Energia en la Industria Ceramica", Universidad del Atlantico y Universidad Autonoma de Occidente. pdf.

[4] Direccion General de Electrcidad, Ministerio de Energia y Minas. "Guias de Orientacion del Uso Eficiente de la Energia y de Diagnostico Energetico. Sector Ceramico". Mayo 2008. pdf.

[5] Grupo de Gestion Eficiente de Energia, KAI. Universidad del Atlantico. "Manual de Procedimiento para la Caracterizacion y Diagnostico Energetico”. Junio 2011. pdf.

[6] Unidad de Planeacion Minero-Energetica, Republica de Colombia, Ministeria de Minas y Energia. "Determinacion de Eficiencia Energetica en el Subsector Industrial Colombiano de Ladrillo, Vidrio y Ceramica". Octubre 2001.

[7] Libro de información de la empresa Ladrillera Barranquilla Ltda. Catalogo de Ventas. 2009.

[8] J. Campos. Universidad del Atlantico. "Caracterizacion Energetica: el primer paso hacia el uso racional de la energia". monografias, [en linea]. http://www.monografias.com/trabajos14/caraenergetica/c araenergetica.shtml.

[9] UPME y Colciencias. Universidad del Atlantico y Universidad Autonoma de Occidente. "Guia para la Implementación de Sistemas de Gestión Integrla de la Energía", pdf.

[10] UPME y Colciencias. Universidad del Atlantico y Universidad Autonoma de Occidente. "Herramientas para el Análisis de Caracterización de la Eficiencia Energética”. pdf. 